\title{
Preparation, Characterization, and Properties of In Situ Formed Graphene Oxide/Phenol Formaldehyde Nanocomposites
}

\author{
Weihua Xu, ${ }^{1,2}$ Chun Wei, ${ }^{1,2}$ Jian Lv, ${ }^{1,2}$ Hongxia Liu, ${ }^{1,2}$ Xiaohua Huang, ${ }^{1,2}$ and Tianxi Liu ${ }^{1,2}$ \\ ${ }^{1}$ Key Laboratory of New Processing Technology for Nonferrous Metals and Materials, Ministry of Education, \\ Guilin University of Technology, Guilin 541004, China \\ ${ }^{2}$ College of Materials Science \& Engineering, Guilin University of Technology, Guilin 541004, China
}

Correspondence should be addressed to Chun Wei; 1005668130@qq.com

Received 27 February 2013; Accepted 15 April 2013

Academic Editor: Guohua Chen

Copyright (C) 2013 Weihua Xu et al. This is an open access article distributed under the Creative Commons Attribution License, which permits unrestricted use, distribution, and reproduction in any medium, provided the original work is properly cited.

\begin{abstract}
Graphene oxide (GO) has shown great potential to be used as fillers to develop polymer nanocomposites for important applications due to their special 2D geometrical structure as well as their outstanding mechanical, thermal, and electrical properties. In this work, GO was incorporated into phenol formaldehyde (PF) resin by in situ polymerization. The morphologies and structures of GO sheets were characterized by FTIR, XRD, and AFM methods. The structure and properties of the GO/PF nanocomposites were characterized using FTIR, XRD, DSC, and TGA methods. Effects of GO content, reactive conditions, and blending methods on the structure and properties of GO/PF nanocomposites were studied. It was found that due to the well dispersion of GO sheets in polymer matrix and the strong interfacial interaction between the GO sheets and PF matrix, the thermal stability and thermal mechanical properties of the GO/PF nanocomposites were greatly enhanced.
\end{abstract}

\section{Introduction}

Phenol formaldehyde (PF) resin has been widely used in building various functional structure materials and coatings due to their high mechanical strength, electrical insulating, flame retardant resistance, fuming rate, and their dimension stability $[1,2]$. However, it still suffers from the brittleness and oxidation risks because of their special methylene-phenolic structure [3]. Thus, many researchers are now trying to find good solutions to enhance the mechanical and the thermal properties of PF resin.

Graphene oxide, one of the most important derivatives of graphene, is structurally similar to graphene. However, the surface of GO contains large numbers of hydrophilic functional groups, such as carbonyl, carboxyl, epoxy, and hydroxyl [4-6], which afforded GO with excellent processability, dispersibility [7], and the compatibility with the polymer; thus GO becomes a promising functional nanoreinforcing material for various polymer and organic molecules to approach different advanced applications [8]. Mohamadi et al. explored functionalization of graphene sheets via chemically grafting of PMMA through in situ polymerization, which resulted in the significant increase of the thermal stability and the glass transition temperature of PMMA. These can be attributed to the covalently bonding to graphene nanosheets [9]. Dideykin et al. prepared functionalized graphene oxide with reactive epoxy groups to obtain polymer nanocomposites via in situ thermal polymerization, and the mechanical, electrical, and thermal properties of the epoxy nanocomposites are efficiently enhanced [10].

In this paper, we focused on the preparation and characterization of $\mathrm{GO} / \mathrm{PF}$ resin nanocomposites. Taking advantage of water solubility of GO [11, 12], in situ polymerization was used to prepare GO/PF nanocomposites to resolve the dispersity of GO in PF matrix. On the other hand, the strong interfacial interactions produced by the active groups of GO sheets and PF matrix may improve the properties of the nanocomposites.

\section{Experimental Section}

2.1. Materials. Flake graphite ( $325 \mathrm{mech}$ ) was purchased from intersci reagent Co. Sulfuric acid, potassium permanganate, 
sodium nitrate, hydrogen peroxide $(30 \%, w / w)$, hydrochloric acid, phenol, and formaldehyde aqueous solution were purchased from Xilong chemical Co., Ltd. Oxalic acid was purchased from Tianjin northern medical chemical reagent plant. Hexamethylene tetramine was purchased from Kelong chemical reagent plant.

2.2. Preparation of GO. The oxidized graphite was synthesized from flake graphite powder ( 325 mesh) by a modified Hummers method $[13,14]$. Firstly, $\mathrm{H}_{2} \mathrm{SO}_{4}$ was added into a flask cooled in an ice-water bath. After $\mathrm{NaNO}_{3}$ and flake graphite were also added to the flask, $\mathrm{KMnO}_{4}$ was slowly added with continuous stirring for $1.5 \mathrm{~h}$. The ice-water bath was then removed and the temperature of the suspension brought to $35^{\circ} \mathrm{C}$, where it maintained for $1 \mathrm{~h}$. Subsequently, about $200 \mathrm{~mL}$ of deionized water was slowly added into the flask, causing violent effervescence and an increase in temperature to $98^{\circ} \mathrm{C}$. The diluted suspension was maintained at this temperature for $30 \mathrm{~min}$. At the end of reaction, $30 \%$ hydrogen peroxide was added into the mixture in order to reduce the residual permanganate and manganese dioxide. Filtering the mixture, the final product was purified by rinsing with a $5 \%$ hydrochloric acid solution. The dry oxidized graphite was obtained after washing with deionized water to neutral and drying at $65^{\circ} \mathrm{C}$ in vacuum $[15,16]$.

The oxidized graphite was dispersed in distilled water to prepare $1 \mathrm{mg} / \mathrm{mL}$ of suspension [6, 17]. By ultrasonic dispersion and centrifugation, GO dispersion in water was obtained. At last, dried at $80^{\circ} \mathrm{C}$ in vacuum for $12 \mathrm{~h}$, the product was $\mathrm{GO}$ powder.

\subsection{Preparation of GO/PF Resin In Situ Nanocomposites.} A certain weight of GO powders was mixed with phenol and formaldehyde solution in a $250 \mathrm{~mL}$ flask and then ultrasonicated for $15 \mathrm{mins}$. Then, $2 \%(\mathrm{w} / \mathrm{w})$ of oxalic acid was added into the above mixture, and the polymerization was conducted at $85^{\circ} \mathrm{C}$ for $4 \mathrm{~h}$. The final product was washed with hot deionized water to remove the excess phenol and dried at $140^{\circ} \mathrm{C}$ for $30 \mathrm{~min}$; the in situ prepared $\mathrm{GO} / \mathrm{PF}$ nanocomposites were then obtained.

2.4. Characterization. Infrared spectra ( $\mathrm{KBr}$ disk) were recorded on a Nicolet Nexus 470 Fourier transform infrared spectroscopy (FTIR) spectrometer. Differential scanning calorimetry (DSC) was conducted on a Netzsch DSC204 instrument using indium standards for calibration. $\mathrm{N}_{2}$ $(20 \mathrm{~mL} / \mathrm{min}$ ) was employed as the purge gas for the sample and reference cells. Thermogravimetric analysis (TGA) was performed on a TA Q500 instrument with a heating rate of $10^{\circ} \mathrm{C} / \mathrm{min}$ in an $\mathrm{N}_{2}$ flow. Wide-angle X-ray diffraction (WAXD) was carried out on a PANalytical B.V. X'Pert PRO $\mathrm{X}$-ray diffractometer. Atomic force microscope (AFM) was performed on an NT-MDT instrument, tapping mode. Transmission electron microscope (TEM) was performed on a JEM-2100 instrument. Scanning electron microscope (SEM) was performed on a JSM-6380LV instrument. Dynamic thermomechanical analysis (DMA) was performed on a TA

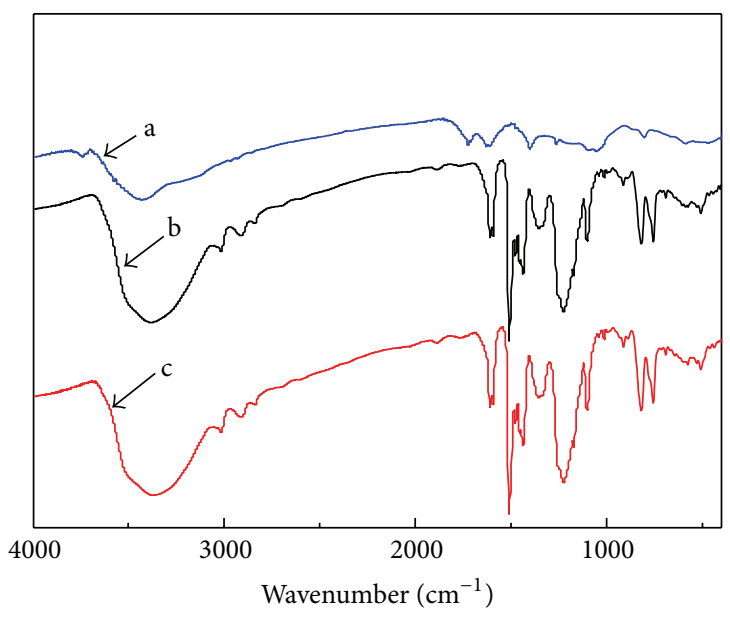

a: GO

b: pure $\mathrm{PF}$

c: $\mathrm{GO} / \mathrm{PF}$

FIGURE 1: FTIR spectrum of GO (a), pure PF (b), and GO/PF in situ nanocomposites (c).

DMA-Q800 instrument; the sample size is $40 \mathrm{~mm} \times 10 \mathrm{~mm} \times$ $4 \mathrm{~mm}$ with a heating rate of $3^{\circ} \mathrm{C} / \mathrm{min}$ from $50^{\circ} \mathrm{C}$ to $300^{\circ} \mathrm{C}$.

\section{Results and Discussion}

3.1. Structure and Morphology of GO/PF Nanocomposites. The FTIR spectra of GO, PF, and GO/PF in situ nanocomposites are shown in Figure 1. From Figure 1(a), we can see that the peaks at $1053 \mathrm{~cm}^{-1}$ and $1262 \mathrm{~cm}^{-1}$ are the stretching vibrations of $\mathrm{C}-\mathrm{O}$ and $\mathrm{C}-\mathrm{O}-\mathrm{C}$, respectively. The peak at $1401 \mathrm{~cm}^{-1}$ presents the $\mathrm{C}-\mathrm{OH}$ stretching vibration. The stretching vibration peaks of $\mathrm{C}=\mathrm{O}$ and $-\mathrm{OH}$ are observed at $1724 \mathrm{~cm}^{-1}$ and $3429 \mathrm{~cm}^{-1}$, respectively. The peak at $1628 \mathrm{~cm}^{-1}$ is the characteristic peak of interlayer water molecules [18]. The above characteristic peaks show that the synthetic GO contains large numbers of functional groups such as carbonyl, carboxyl, epoxy, and hydroxyl, which endue GO with good hydrophilicity and powerful interfacial bonding with PF matrix [19].

The Ortho-bit linear phenolic resin presents two absorption peaks at $756 \mathrm{~cm}^{-1}$ and $818 \mathrm{~cm}^{-1}$. The peak at $1101 \mathrm{~cm}^{-1}$ is the stretching vibration of $\mathrm{C}-\mathrm{C}$ in benzene ring. The peak present at $1225 \mathrm{~cm}^{-1}$ is the $-\mathrm{CO}-$ stretching vibration peak of phenol. The vibration peak of $\mathrm{C}=\mathrm{C}$ and stretching vibration peaks of $-\mathrm{OH}$ in benzene ring are observed at $1610 \mathrm{~cm}^{-1}$ and $3384 \mathrm{~cm}^{-1}$, respectively. So, the results show that phenol formaldehyde resin (Figure 1(b)) was synthesized successfully. Compared with the spectrum of pure phenol formaldehyde resin, the absorption peaks of $\mathrm{GO} / \mathrm{PF}$ in situ nanocomposites (Figure 1(c)) do not change. One possible reason is that the characteristic peaks of groups in GO were covered up by that of PF resin. On the other hand, it presents that there are no chemical reactions between GO with PF 


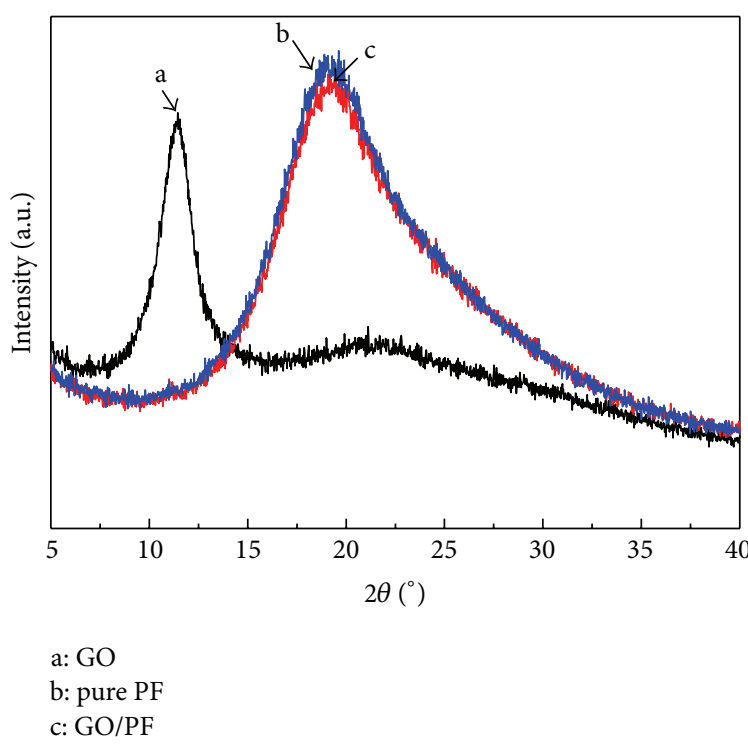

Figure 2: Wide-angle X-ray diffraction patterns of GO (a), pure PF (b), and GO/PF in situ nanocomposites (c).

resin matrix, and GO has interpenetrated into $\mathrm{PF}$ resin matrix during in situ polymerization.

$\mathrm{GO}, \mathrm{PF}$, and GO/PF in situ nanocomposites were examined by WAXD with $2 \theta$ ranging from 5 to $40^{\circ}$, and the results are shown in Figure 2. From Figure 2, we can see that diffraction peak of GO appears at $2 \theta=11.3^{\circ}$ [20]. The WAXD pattern of GO/PF in situ nanocomposites is similar to that of pure PF. Both of them have the same diffraction peak at $2 \theta \approx 20^{\circ}$. However, diffraction peak of GO in GO/PF in situ nanocomposites disappears, which can be explained by that GO has interpenetrated into PF resin, and the interfacial interaction with the matrix can affect the crystallization of GO.

Atomic force microscope (AFM) images of GO are shown in Figure 3. From Figure 3 we can see that the obtained GO are single sheet with about $0.86 \mathrm{~nm}$ thickness and irregular surface area. From TEM image of GO shown in Figure 4, we can further see that GO sheet is irregular, and the folded GO sheet presents that it has lamellar structure and excellent flexility. According to the above states, we can say that GO with single sheet and 2D nanometer scale was successfully fabricated.

\subsection{Thermal Stability of GO/PF Nanocomposites. TGA was} utilized to characterize the thermal stability of PF and GO/PF nanocomposites. It was studied on the basis of $5 \%$ and $15 \%$ weight losses of the polymer and the residual mass at $700^{\circ} \mathrm{C}$. TGA curves of pure PF and GO/PF in situ nanocomposites with $0.25 \%, 0.5 \%$, and $1 \%$ of GO are shown in Figure 5, and the data are summarized in Table 1. From Figure 5 and Table 1, we can see that the temperature of $5 \%$ weight losses of the pure $\mathrm{PF}$ is $191.7^{\circ} \mathrm{C}$, and the corresponding temperatures of $\mathrm{GO} / \mathrm{PF}$ in situ nanocomposites increase from $235^{\circ} \mathrm{C}$ to $247^{\circ} \mathrm{C}$ as the contents of GO increase from $0.25 \%$ to $1 \%$. Compared to pure $\mathrm{PF}, \mathrm{GO} / \mathrm{PF}$ in situ nanocomposites have a higher
TABLE 1: Results of TGA curves of PF and GO/PF in situ nanocomposites.

\begin{tabular}{lrccc}
\hline $\begin{array}{l}\text { GO contents } \\
(\%)\end{array}$ & $T_{d 5 \%}{ }^{\mathrm{a}}\left({ }^{\circ} \mathrm{C}\right)$ & $T_{d 15 \%}{ }^{\mathrm{b}}\left({ }^{\circ} \mathrm{C}\right)$ & $T_{d \max }{ }^{\mathrm{c}}\left({ }^{\circ} \mathrm{C}\right)$ & $\begin{array}{c}\text { Residual } \\
\text { mass }^{\mathrm{d}}(\%)\end{array}$ \\
\hline 0 & 191.7 & 257.4 & 395.1 & 45.20 \\
0.25 & 235.5 & 382.5 & 402.3 & 46.85 \\
0.5 & 240.9 & 361.5 & 392.7 & 43.74 \\
1 & 247.5 & 361.5 & 391.2 & 43.35 \\
\hline
\end{tabular}

${ }^{a}$ The decomposition temperature at weight loss of $5 \% .{ }^{b}$ The decomposition temperature at weight loss of $15 \%$. ${ }^{c}$ The temperature at the maximum decomposition rate. ${ }^{\mathrm{d}}$ Residual mass at $700^{\circ} \mathrm{C}$.

TABLE 2: Results of DSC curing temperature of GO/PF in situ nanocomposites.

\begin{tabular}{lcccc}
\hline GO contents $(\%)$ & 0 & 0.25 & 0.5 & 1 \\
Curing temperature $\left({ }^{\circ} \mathrm{C}\right)$ & 157.9 & 155.7 & 156.1 & 156.4 \\
\hline
\end{tabular}

temperature of $5 \%$ weight losses. Similarly, the temperature of $15 \%$ weight losses of $\mathrm{GO} / \mathrm{PF}$ in situ nanocomposites with $0.25 \%, 0.5 \%$, and $1 \%$ of GO is higher than that of pure PF. However, $T_{d \max }$ of GO/PF in situ nanocomposites loaded $0.5 \%$ and $1 \%$ of $\mathrm{GO}$ are, respectively, $392.7^{\circ} \mathrm{C}$ and $391.2^{\circ} \mathrm{C}$, which are lower than that $\left(395.1^{\circ} \mathrm{C}\right)$ of pure $\mathrm{PF}$ resin. $T_{d} \max$ of $\mathrm{GO} / \mathrm{PF}$ in situ nanocomposites loaded $0.25 \%$ of $\mathrm{GO}$ is $402.3^{\circ} \mathrm{C}$ higher than that of pure PF. Besides, the temperature of $15 \%$ weight losses of $\mathrm{GO} / \mathrm{PF}$ in situ nanocomposites loaded $0.25 \%$ of $\mathrm{GO}$ is up to $382^{\circ} \mathrm{C}$ which is higher than that of the other three samples. For pure PF resin, initial decomposition took place at $191.7^{\circ} \mathrm{C}$ far lower than its $\mathrm{Tg}$ $\left(229^{\circ} \mathrm{C}\right.$ ) (see Figure 6(b)). For GO/PF in situ nanocomposites, initial decomposition took place at about $240^{\circ} \mathrm{C}$ near to their $\mathrm{Tg}$. The possible reason is that GO can be well homogenously dispersed in the matrix by in situ polymerization. At the same time, GO with numerous active groups and PF matrix can produce a strong interfacial interaction which can restrain the molecular segmental mobility of PF and prevent PF from initial decomposition. Although the molecular segmental of PF starts to move at the temperature higher than $\mathrm{Tg}$, the restriction for the molecular segmental mobility of PF becomes more obvious. It results in that GO/PF in situ nanocomposites exhibit better thermal stability with higher about $100^{\circ} \mathrm{C}$ temperature of $15 \%$ weight losses than pure $\mathrm{PF}$. With the temperature further increased, the interfacial interaction with pure PF could be weakened and even broken as the full decomposition of pure PF happens. Here, GO has little effect on thermal stability of nanocomposites. In conclusion, due to the powerful interfacial interaction between GO and PF matrix, the thermal stability of GO/PF nanocomposite especially with $0.25 \%$ of GO is greatly enhanced by in situ polymerization.

DSC was measured by heating $\mathrm{PF}$ and GO/PF samples from $25^{\circ} \mathrm{C}$ to $300^{\circ} \mathrm{C}$ at $10^{\circ} \mathrm{C} / \mathrm{min}$, in an $\mathrm{N}_{2}$ atmosphere. The results are summarized in Table 2 . It is found that the curing temperatures of $\mathrm{PF}$ and $\mathrm{GO} / \mathrm{PF}$ in situ nanocomposites are a little different. Compared to $\mathrm{PF}$, the curing temperature of $\mathrm{GO} / \mathrm{PF}$ nanocomposites was about $156^{\circ} \mathrm{C}$ slightly lower than 


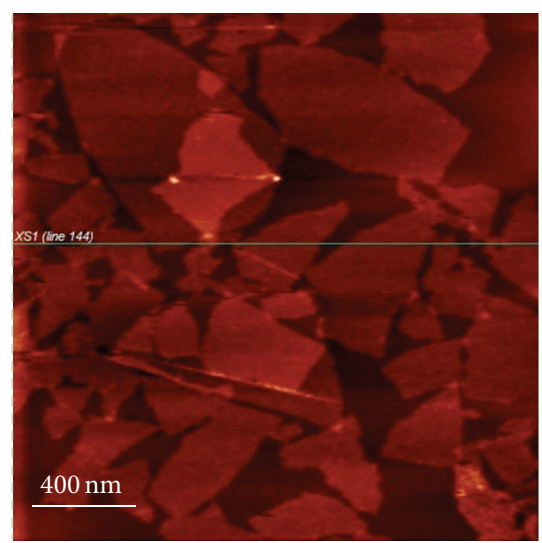

(a)

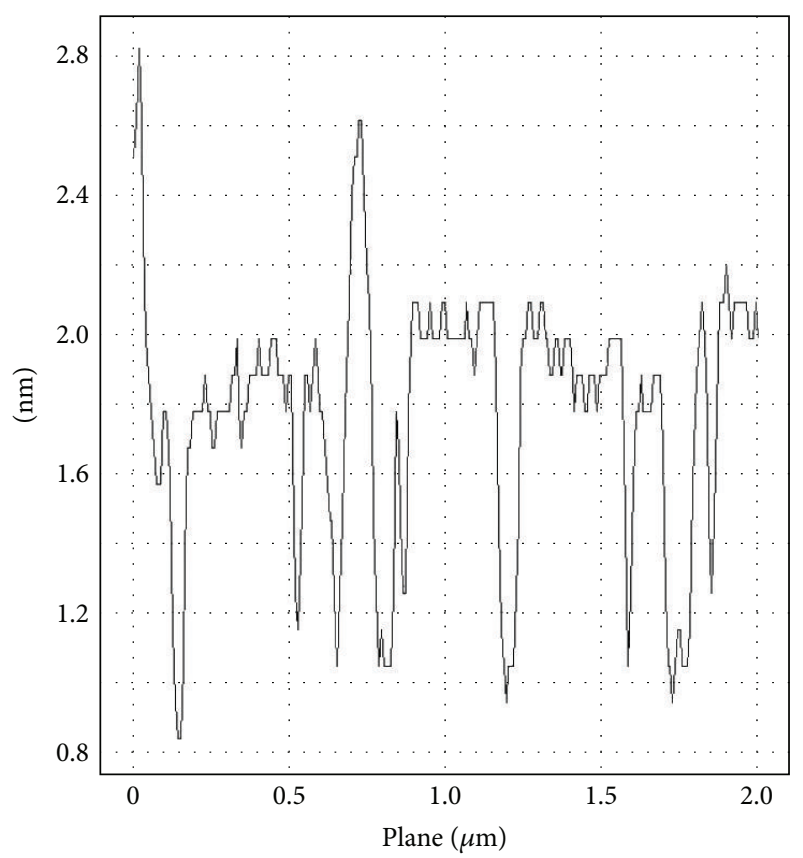

(b)

FIGURE 3: (a) AFM height image of GO; (b) height profile along the blue line in (a).

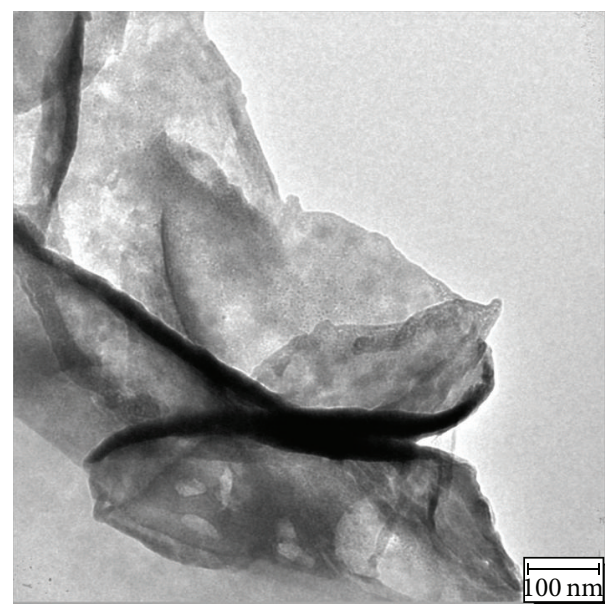

FIGURE 4: TEM image of GO.

that $\left(158^{\circ} \mathrm{C}\right)$ of pure $\mathrm{PF}$. The curing temperature of $\mathrm{GO} / \mathrm{PF}$ in situ nanocomposites does not significantly change, which shows that GO and PF have good compatibility.

\subsection{Thermal Mechanical Properties of GO/PF Nanocomposites.} Dynamic thermomechanical analysis (DMA) was used to investigate the thermal mechanical properties of $\mathrm{GO} / \mathrm{PF}$ nanocomposites. Figures 6(a) and 6(b) show the storage modulus and $\tan \delta$ value of $\mathrm{GO} / \mathrm{PF}$ in situ nanocomposites with different loading contents of $\mathrm{GO}$ at the temperature from $50^{\circ} \mathrm{C}$ to $300^{\circ} \mathrm{C}$, respectively. As Figure 6(a) shows, the storage

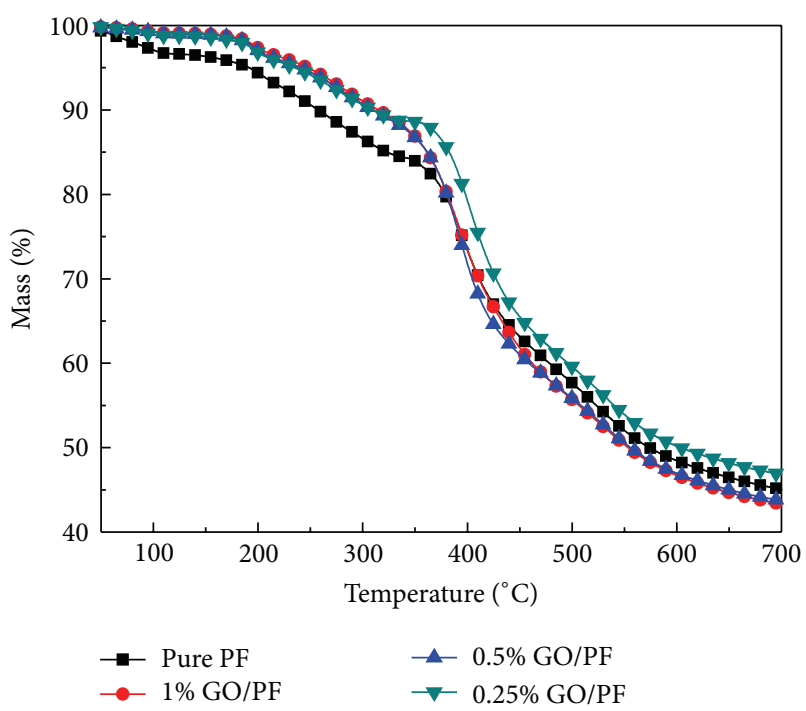

FIGURE 5: TGA curves of PF and GO/PF in situ nanocomposites.

modulus of GO/PF in situ nanocomposites has increased significantly. When $0.5 \%$ and $1 \%$ of GO were loaded, the storage modulus of the composites reached $10059 \mathrm{MPa}$ and $9975 \mathrm{MPa}$, which were increased by $79.8 \%$ and $78.3 \%$ than pure $\mathrm{PF}(E=5595 \mathrm{MPa})$, respectively. The increase of storage modulus of GO/PF in situ nanocomposites mainly results from the high mechanical modulus of GO and the reinforcing effect of GO in the PF matrix. 


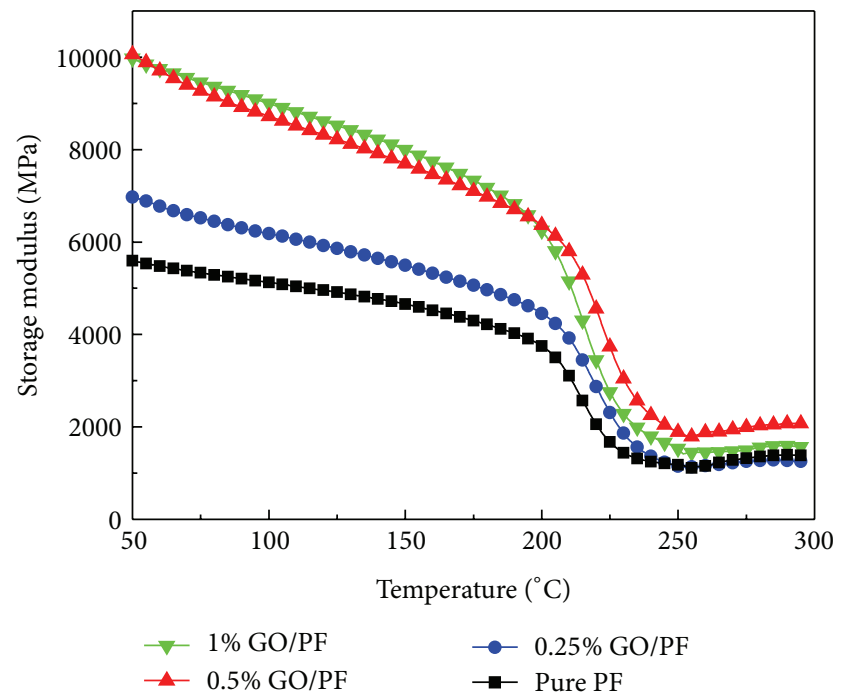

(a)

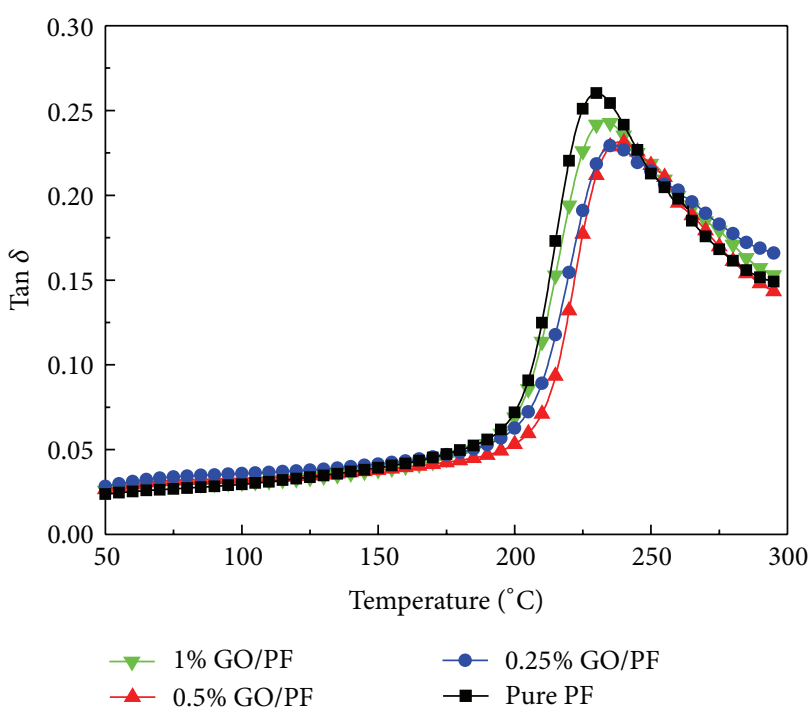

(b)

Figure 6: DMA curves of GO/PF in situ nanocomposites.

In Figure 6(b), we can see that $\tan \delta$ peak of pure PF temperature at $229^{\circ} \mathrm{C}$ meaning Tg measured by DMA moves to higher temperature as the $\mathrm{GO}$ is added. $\mathrm{Tg}$ of $\mathrm{GO} / \mathrm{PF}$ in situ nanocomposites loaded $0.25 \%, 0.5 \%$, and $1 \%$ of GO is $236.6^{\circ} \mathrm{C}, 238.6^{\circ} \mathrm{C}$, and $233.1^{\circ} \mathrm{C}$, respectively. When $0.5 \%$ of GO is loaded, $\mathrm{Tg}$ of $\mathrm{GO} / \mathrm{PF}$ in situ nanocomposites reaches the mixium higher than $9^{\circ} \mathrm{C}$ pure PF. This can be explained by that a certain amount of GO was well dispersed in the PF matrix by in situ polymerization. Meanwhile, the active groups of GO can form powerful interfacial bonding with PF matrix and limit the molecular segmental mobility of PF. With the content of GO further increased, Tg of $\mathrm{GO} / \mathrm{PF}$ in situ nanocomposites is oppositely decreased. The possible reason is that an excess of GO could aggregate and affect its dispersivity in the PF matrix which is leading to the interaction between GO and PF matrix weakened. So, according to the above states, we can conclude that the thermal mechanical property of GO/PF nanocomposites is improved significantly by in situ polymerization.

\section{Conclusions}

Graphene oxide was synthesized by a modified Hummers method, and GO/PF composites were prepared through in situ polymerization. The results show that the nanoscale graphene oxide can be well dispersed in the PF matrix resin, and the thermal stability and dynamic mechanical properties of $\mathrm{GO} / \mathrm{PF}$ composites were significantly improved because of the powerful interfacial interaction between GO and PF resin matrix.

\section{Acknowledgments}

The authors would like to acknowledge the National Natural Science Foundation of China (Grant nos. 51163003, 51263005, and 51163004) and the Innovation Team of Guangxi Universities' Talent Highland for financial support.

\section{References}

[1] A. Gardziella, L. A. Pilato, and A. Knop, Phenolic Resins, Springer, New York, NY, USA, 2000.

[2] A. Gardziella, L. A. Pilato, and A. Knop, Phenolic Resins: Chemistry, Applications, Standardization, Safety and Ecology, Springer, New York, NY, USA, 1985.

[3] R. W. Martin, The Chemistry of Phenolic Resins, John Wiley \& Sons, New York, NY, USA, 1956.

[4] S. Stankovich, R. D. Piner, S. T. Nguyen, and R. S. Ruoff, "Synthesis and exfoliation of isocyanate-treated graphene oxide nanoplatelets," Carbon, vol. 44, no. 15, pp. 3342-3347, 2006.

[5] J. Longun and J. O. Iroh, "Nano-graphene/polyimide composites with extremely high rubbery plateau modulus," Carbon, vol. 50, pp. 1823-2832, 2012.

[6] T. Szabó, O. Berkesi, and I. Dékány, "DRIFT study of deuteriumexchanged graphite oxide," Carbon, vol. 43 , no. 15 , pp. 31863189, 2005.

[7] T. Ramanathan, A. A. Abdala, S. Stankovich et al., "Functionalized graphene sheets for polymer nanocomposites," Nature Nanotechnology, vol. 3, no. 6, pp. 327-331, 2008.

[8] S. Stankovich, D. A. Dikin, G. H. B. Dommett et al., "Graphenebased composite materials," Nature, vol. 442, no. 7100, pp. 282286, 2006.

[9] H. Liu, Y. Q. Li, T. M. Wang, and Q. H. Wang, "In situ synthesis and thermal, tribological properties of thermosetting polyimide/graphene oxide nanocomposites," Journal of Materials Science, vol. 47, pp. 1867-1874, 2012.

[10] A. Dideykin, A. E. Aleksenskiy, D. Kirilenko et al., "Monolayer graphene from graphite oxide," Diamond \& Related Materials, vol. 20, no. 2, pp. 105-108, 2011.

[11] D. Li, M. B. Müller, S. Gilje, R. B. Kaner, and G. G. Wallace, "Processable aqueous dispersions of graphene nanosheets," Nature Nanotechnology, vol. 3, no. 2, pp. 101-105, 2008. 
[12] S. Park, K. S. Lee, G. Bozoklu, W. Cai, S. B. T. Nguyen, and R. S. Ruoff, "Graphene oxide papers modified by divalent ionsenhancing mechanical properties via chemical cross-linking," ACS Nano, vol. 2, no. 3, pp. 572-578, 2008.

[13] W. S. Hummers and R. E. Offeman, "Preparation of graphitic oxide," Journal of the American Chemical Society, vol. 80, no. 6, p. 1339, 1958.

[14] M. Mermoux and Y. Chabre, "Formation of graphite oxide," Synthetic Metals, vol. 34, no. 1-3, pp. 157-162, 1989.

[15] C. Nethravathi and M. Rajamathi, "Chemically modified graphene sheets produced by the solvothermal reduction of colloidal dispersions of graphite oxide," Carbon, vol. 46, no. 14, pp. 1994-1998, 2008.

[16] A. A. Balandin, S. Ghosh, W. Bao et al., "Superior thermal conductivity of single-layer graphene," Nano Letters, vol. 8, no. 3, pp. 902-907, 2008.

[17] M. D. Stoller, S. Park, Z. Yanwu, J. An, and R. S. Ruoff, "Graphene-Based ultracapacitors," Nano Letters, vol. 8, no. 10, pp. 3498-3502, 2008.

[18] P. Ramesh, S. Bhagyalakshmi, and S. Sampath, "Preparation and physicochemical and electrochemical characterization of exfoliated graphite oxide," Journal of Colloid and Interface Science, vol. 274, no. 1, pp. 95-102, 2004.

[19] M. Fang, K. Wang, H. Lu, Y. Yang, and S. Nutt, "Covalent polymer functionalization of graphene nanosheets and mechanical properties of composites," Journal of Materials Chemistry, vol. 19, no. 38, pp. 7098-7105, 2009.

[20] Y. Matsuo, K. Tahara, and Y. Sugie, "Synthesis of poly(ethylene oxide)-intercalated graphite oxide," Carbon, vol. 34, no. 5, pp. 672-674, 1996. 

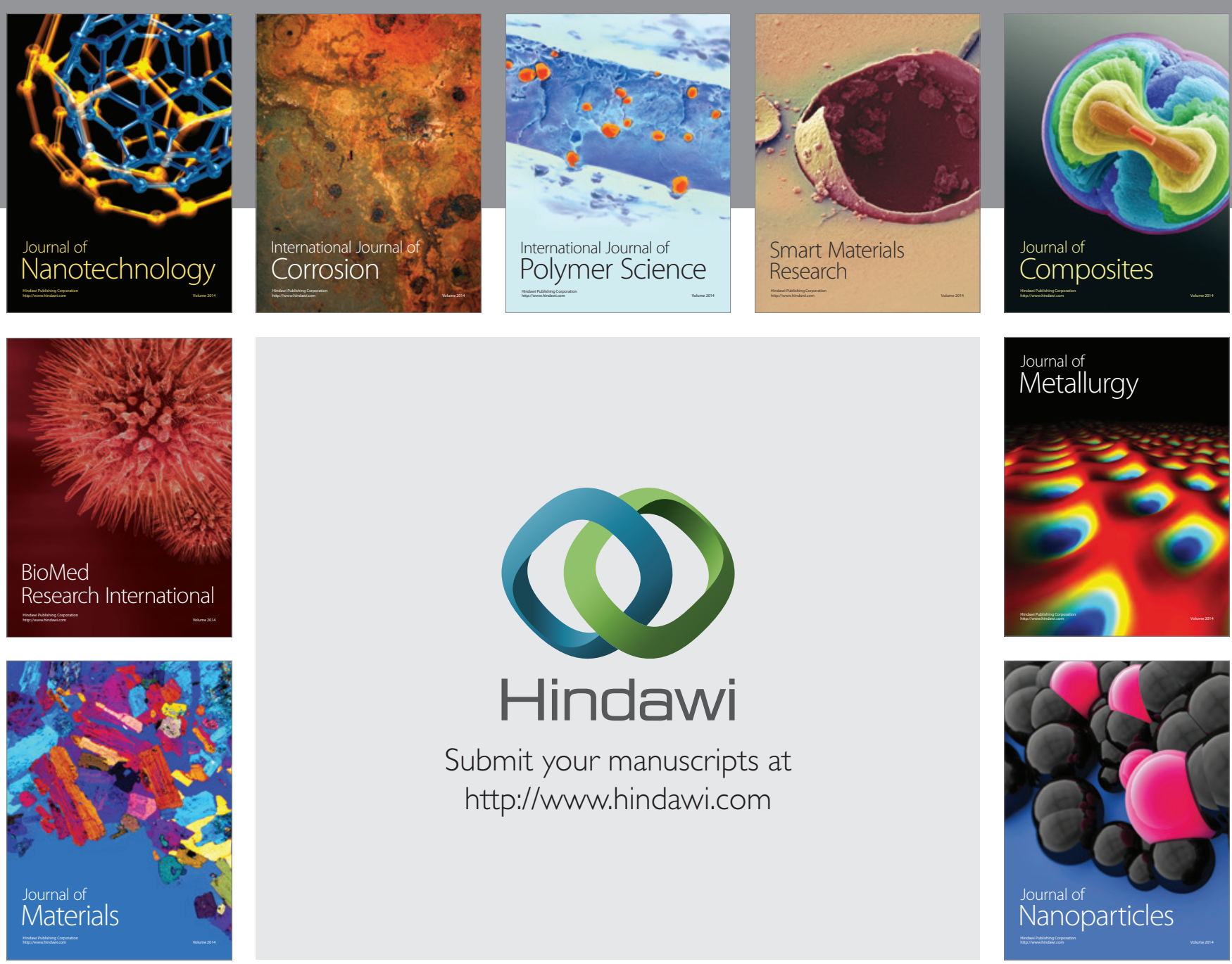

Submit your manuscripts at http://www.hindawi.com
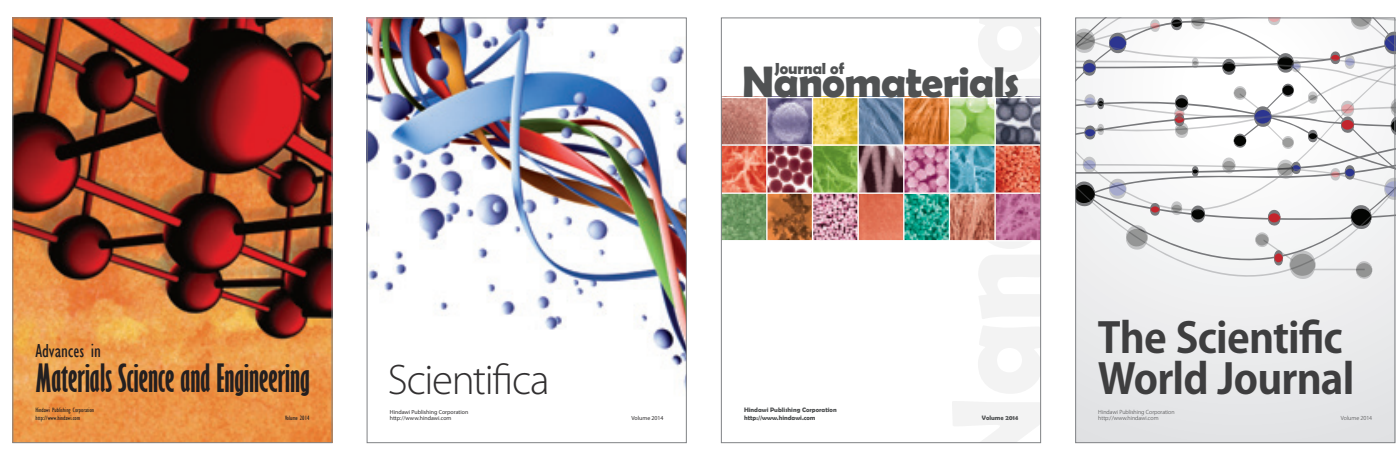

\section{The Scientific World Journal}
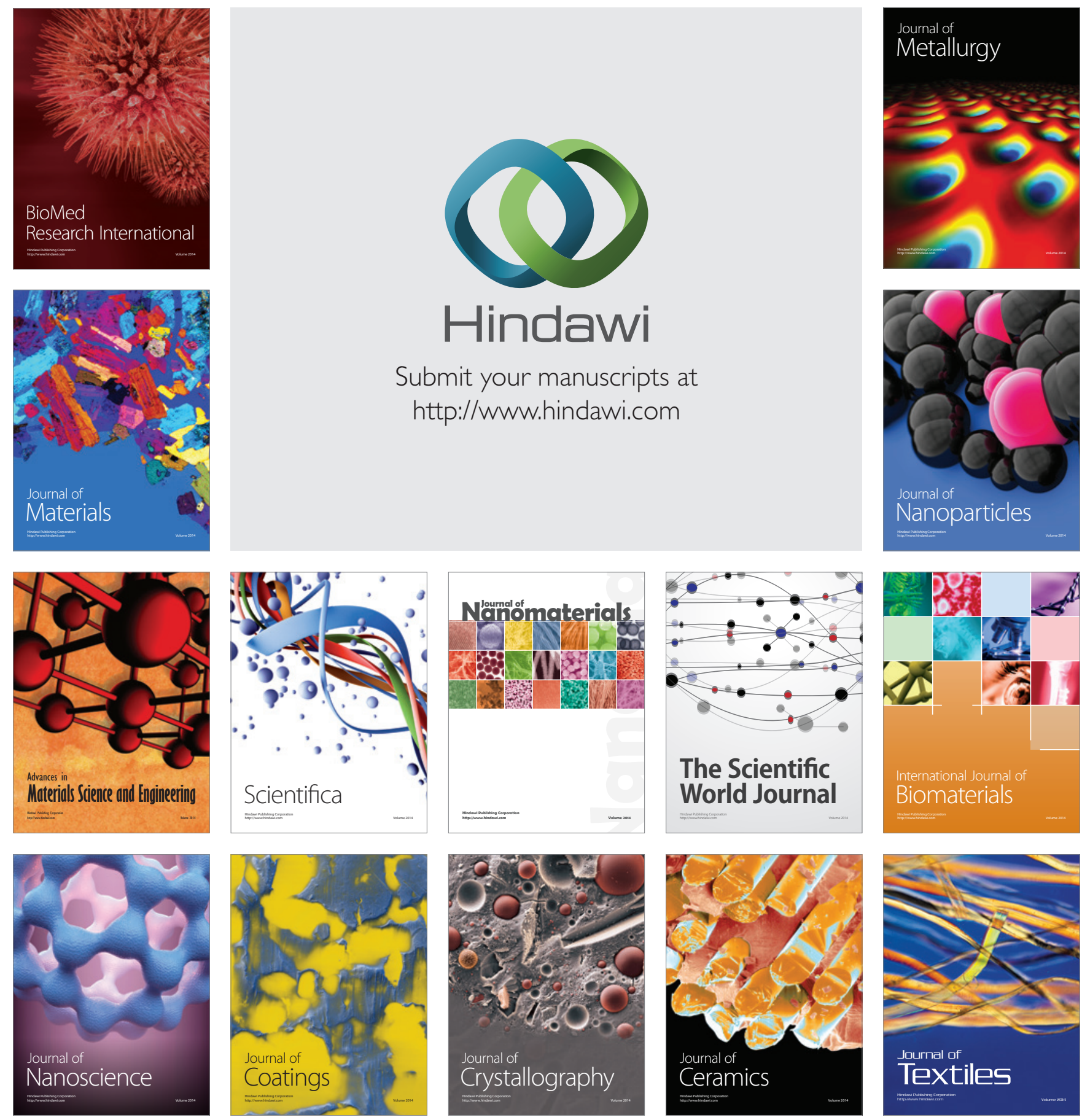